\title{
Selective ligand-free cobalt-catalysed reduction of esters to aldehydes or alcohols.
}

\author{
Vincent Rysak, ${ }^{\mathrm{a}, \mathrm{b}}$ Armel Descamps-Mandine, ${ }^{\mathrm{c}}$ Pardis Simon, ${ }^{\mathrm{a}, \mathrm{d}}$ Florent Blanchard, ${ }^{\mathrm{a}, \mathrm{e}}$ Laurence Burylo, ${ }^{\mathrm{a}, \mathrm{e}}$ Martine \\ Trentesaux, ${ }^{a, d}$ Maxence Vandewalle, ${ }^{a, e}$ Vincent Collière, ${ }^{f}$ Francine Agbossou-Niedercorn*a,b and Christophe \\ Michon*a,b
}

a. Univ. Lille, CNRS, Centrale Lille, ENSCL, Univ. Artois, UMR 8181 - UCCS - Unité de Catalyse et Chimie du Solide, F-59000 Lille, France. E-mail: francine.agbossou@ensc-lille.fr, christophe.michon@ensc-lille.fr

b. ENSCL, UCCS-CCM, (Chimie-C7) CS 90108, 59652 Villeneuve d'Ascq Cedex, France

c. Centre de Microcaractérisation R. Castaing, Univ. Toulouse III - Paul Sabatier, CNRS UMS3623, Espace C.

Ader 3, rue Caroline Aigle 31400 Toulouse, France.

d. UCCS-CH, Université de Lille, Chimie-C3, 59655 Villeneuve d'Ascq, France.

e. $\quad$ ENSCL, UCCS-CS, (Chimie-C7) CS 90108, 59652 Villeneuve d'Ascq Cedex, France.

f. Laboratoire de Chimie de Coordination UPR8241 CNRS, BP 44099205 route de Narbonne 31077 Toulouse cedex 4 France.

Electronic Supplementary Information (ESI) available: [experimental procedures, analytical data, NMR and HRMS spectra, TEM, XPS and DRX data]. See the web.

Cobalt(II) salts combined with $\mathrm{NaBHEt}_{3}$ and eventually a base catalyse efficiently and selectively the reduction of esters to aldehydes or alcohols through hydrosilylation by using phenylsilane. Catalyst characterisations by XRD, XPS, TEM and STEM analyses indicate the materials were partially crystalline with the presence of cobalt nanoparticles. Control experiments suggested low valent $\mathrm{Co}(0)$ was the active catalytic species involved.

\section{Introduction}

Alcohols and aldehydes are important bulk and fine chemicals in organic chemistry. For the production of alcohols, the reduction of carboxylic acid derivatives is one of the main synthetic pathways. ${ }^{1}$ Besides the use of stoichiometric amounts of hydride salts, the reduction of esters can be performed by hydrogenation using heterogeneous catalysts under harsh conditions. ${ }^{1 a, b}$ By comparison, the use of homogeneous catalysts allows more active and selective hydrogenation reactions by operating in milder conditions. Whereas significant achievements were reported using noble metals like ruthenium ${ }^{2}$ the hydrogenation of esters using homogeneous catalysts based on abundant metals, i.e. iron ${ }^{3}$ and manganese, ${ }^{4}$ has been actively studied for several years. At the meantime, homogeneous cobalt catalysts 1-4 were developed for analogous hydrogenation reactions of esters (Scheme 1). ${ }^{5}$ By extension, several cobalt pre-catalysts associated with a ligand were heterogenised to lead to active catalysts for hydrogenation of alkenes and imines. ${ }^{6}$ Interestingly, some of these last reactions were also catalysed under hydrogen by a combination of simple cobalt salts and lithium aluminium hydrides. ${ }^{7}$ By comparison to hydrogen, the use of hydrosilanes as reductants is an area of growing interest for the mild and selective reduction of ester derivatives by using catalysts based on transition metals like $\mathrm{Ti}^{\mathrm{i}}{ }^{\mathrm{8a}-\mathrm{b}} \mathrm{Rh},{ }^{8 \mathrm{e}} \mathrm{Zn},{ }^{8 \mathrm{~d}, \mathrm{~g}, \mathrm{i}} \mathrm{Mo},{ }^{8 \mathrm{ffh}} \mathrm{V},{ }^{8 \mathrm{~h}}$ or on Lewis acids. ${ }^{8 \mathrm{c}}$ Indeed, hydrosilylation, ${ }^{9}$ which operates without any high pressure equipment and high temperature, is an interesting alternative to hydrogenation. Whereas some $\operatorname{iron}^{10}$ and manganese ${ }^{11}$ catalysts were effectively applied to the hydrosilylation of carboxylic acid derivatives, the use of a cobalt catalyst has, to the best of our knowledge, not been reported yet for such a reaction. Regarding the reduction of esters to aldehydes, a selective hydrosilylation reaction can be complementary to the hydroformylation of olefins ${ }^{12}$ and the oxidation of primary alcohols. ${ }^{13}$ Although the reduction of esters to aldehydes is possible by using diisobutylaluminium hydride or lithium tritertbutoxyaluminium hydride, these reagents are not used regularly on a large scale because of their sensitivity and 
capricious reputation. ${ }^{14}$ Hence, though examples are scarce, ${ }^{15,16 \mathrm{~d}}$ the hydrosilylation of esters to aldehydes is a versatile reaction when chemoselectivity issues are encountered.

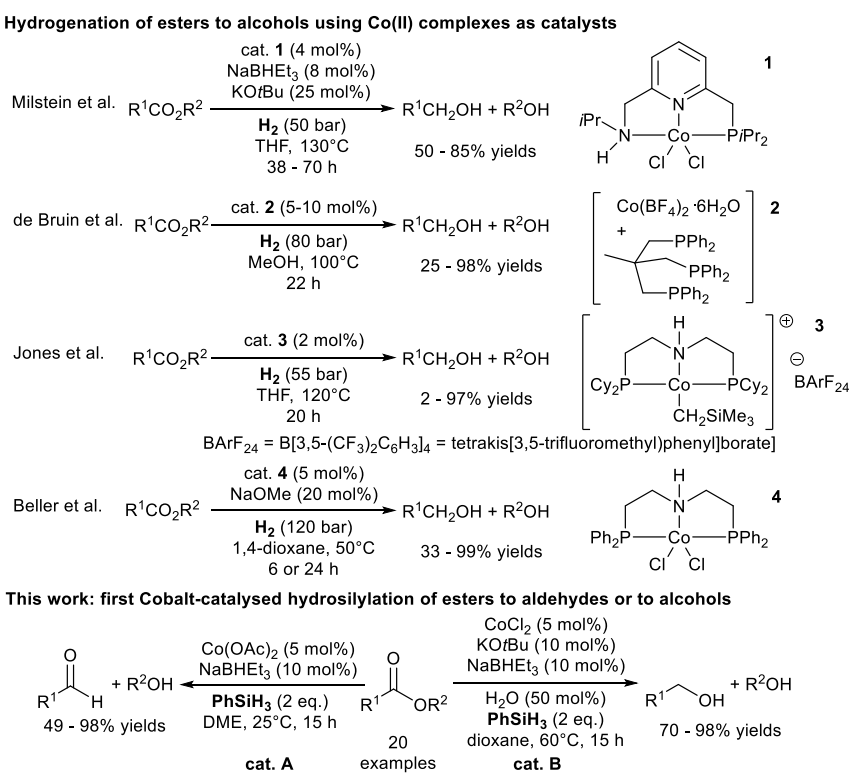

Scheme 1 Cobalt-catalysed reduction of esters through hydrogenation or hydrosilylation reactions.

Indeed, by using transition metal or Lewis acid catalysts, it enables the formation of silyl acetals, ${ }^{9,15,16 \mathrm{~d}}$ which can be converted to aldehydes upon hydrolysis. Following our ongoing interest in iridium catalysed hydrosilylations of carbon-carbon and carbon-heteroatom insaturations, ${ }^{16}$ we turned our attention on cobalt catalysed reactions. We report herein novel highly selective hydrosilylations of esters to aldehydes or alcohols through the use of simple Co(II) catalysts which do not require any costly and air sensitive ligands (Scheme 1).

\section{Results and discussion}

Initially, ethylphenylacetate $\mathbf{5 a}$ was chosen as model substrate to test and optimise the different possible catalysts. A screening of cobalt salts determined $\mathrm{Co}(\mathrm{OAc})_{2}$ and $\mathrm{CoCl}_{2}$ were the best $\mathrm{Co}$ metal sources to combine with $\mathrm{NaBHEt}_{3}$ for the hydrosilylation of ester $\mathbf{5 a}$ to aldehyde $\mathbf{6 a}$ or alcohol 7a (see Tables S1 and S4). Regarding the selective reduction of ester $\mathbf{5 a}$ to aldehyde $\mathbf{6 a}$ using $\mathrm{Co}(\mathrm{OAc})_{2}$ as pre-catalyst (cat. $\mathbf{A}$ ), the hydrosilylation was more

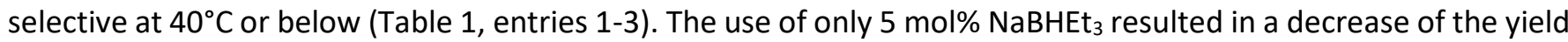
(entry 4) and so did the addition of 50 mol\% of $\mathrm{H}_{2} \mathrm{O}$ (entry 5). The product selectivity proved to be in favour of alcohol 7a while adding $10 \mathrm{~mol} \%$ of $\mathrm{KOtBu}$ (entry 6 ). The use of 2 equivalents of phenysilane proved to be critical in order to form 6a exclusively (entries 2, 7-8). A decrease to $1 \mathrm{~mol} \%$ of $\mathrm{Co}(\mathrm{OAc})_{2}$ loading resulted in a loss of selectivity (entry 9), and a mercury trapping experiment resulted in a decrease of yield and selectivity, some alcohol $7 a$ being observed (entry 10 ). This highlighted that nanoparticles may contribute to the hydrosilylation reaction.

Regarding the selective reduction of ester 5 a to alcohol 7 a using $\mathrm{CoCl}_{2}$ as pre-catalyst (cat. B), the reaction required the addition of $50 \mathrm{~mol} \%$ of water to operate completely (Table 2, entries 1-3). Full conversion and selectivity were obtained at $60^{\circ} \mathrm{C}$ while using 2 equivalents of phenysilane (entries 3, 4-6). Furthermore, the use of $10 \mathrm{~mol} \%$ of $\mathrm{KOtBu}$ and $10 \mathrm{~mol} \%$ of $\mathrm{NaBHEt}_{3}$ proved to be critical for running the hydrosilylation, a change for lower loadings or other additives led to lower conversions and selectivities (Table 2, entries 7-8 and see the Supporting Information Table S5). The catalysis was also perfectly proceeding with $1 \mathrm{~mol} \%$ of $\mathrm{CoCl}_{2}$ (entry 9), and a mercury trapping experiment resulted only in a slight decrease of selectivity, some aldehyde 6a being obtained (entry 10). For both pathways, screening of other ether solvents confirmed DME and 1,4-dioxane were respectively the best for the synthesis of aldehyde $\mathbf{6 a}$ and alcohol $\mathbf{7 a}$ (see the Supporting Information Tables S2, S6). At the exception of 
hexylsilane, replacement of phenylsilane by other silane reagents did not allow any reaction along both hydrosilylation conditions (see Tables S3, S7). Finally, full-conversions were also obtained for reactions at a $3 \mathrm{mmol}$ scale of ester $\mathbf{5 a}$ (Tables S1, S4).

Table 1 Optimisation of the catalytic conditions for the reduction of ester 5 a to aldehyde 6 a (cat. A).

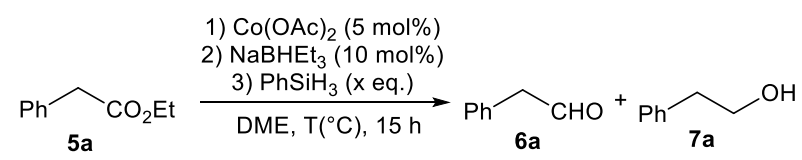

\begin{tabular}{lllllll}
\hline Entry & $\begin{array}{l}\mathbf{T} \\
\end{array}$ & $\begin{array}{l}\text { Silane } \\
\mathbf{(}^{\circ} \mathbf{C}\end{array}$ & $\begin{array}{l}\text { Additive } \\
\text { (eq.) }\end{array}$ & $\begin{array}{l}\text { Yield } \\
\text { (mol\%) }\end{array}$ & $\begin{array}{l}\text { Selectivity (\%) } \\
\text { (\%) }^{\mathbf{a}}\end{array}$ & $\begin{array}{l}\text { 6a / 7a } \\
\end{array}$ \\
\hline 1 & 60 & 2 & - & 100 & 75 & 25 \\
2 & 40 & 2 & - & 100 & 100 & - \\
3 & 25 & 2 & - & 74 & 100 & - \\
$4^{\mathrm{b}}$ & 40 & 2 & - & 93 & 100 & - \\
5 & 40 & 2 & $\mathrm{H}_{2} \mathrm{O}(50)$ & 75 & 100 & - \\
6 & 40 & 2 & $\mathrm{KOtBu}$ & 100 & 27 & 73 \\
7 & 40 & 1.5 & - & 78 & 93 & 7 \\
8 & 40 & 1 & - & 61 & 89 & 11 \\
$9^{c}$ & 40 & 2 & - & 100 & 89 & 11 \\
$10^{\text {d }}$ & 40 & 2 & $\mathrm{Hg}$ & 78 & 81 & 19 \\
\hline
\end{tabular}

a) Determined by GC. b) Reaction with 5 mol\% NaBHEt $_{3}$ instead of 10 mol\%.

c) $1 \mathrm{~mol} \% \mathrm{Co}(\mathrm{OAc})_{2}, 2$ mol\% $\mathrm{NaBHEt}_{3}$. d) $\mathrm{Hg}(0)$ (1 drop).

Table 2 Optimisation of the catalytic conditions for the reduction of ester $\mathbf{5 a}$ to alcohol 7a (cat. B).

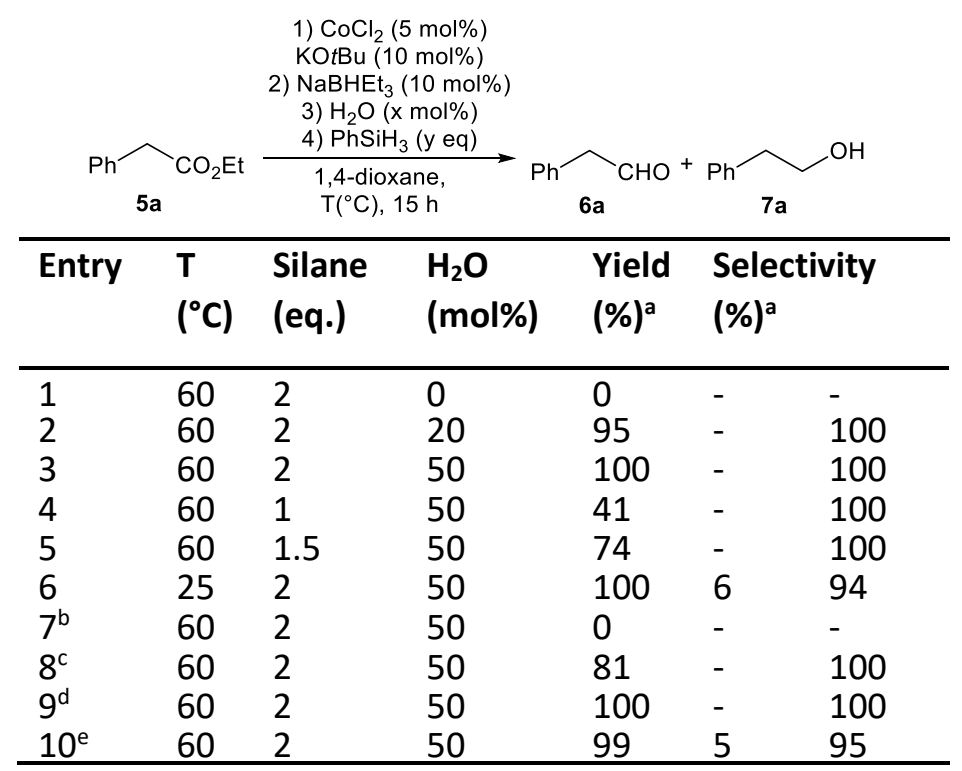

a) Determined by GC. b) No KOtBu used. c) 5 mol\% $\mathrm{NaBHEt}_{3}$.

d) 1 mol\% $\mathrm{CoCl}_{2}, 2$ mol\% NaBHEt, 2 mol\% KOtBu. e) $\mathrm{Hg}(0)$ (1 drop). 


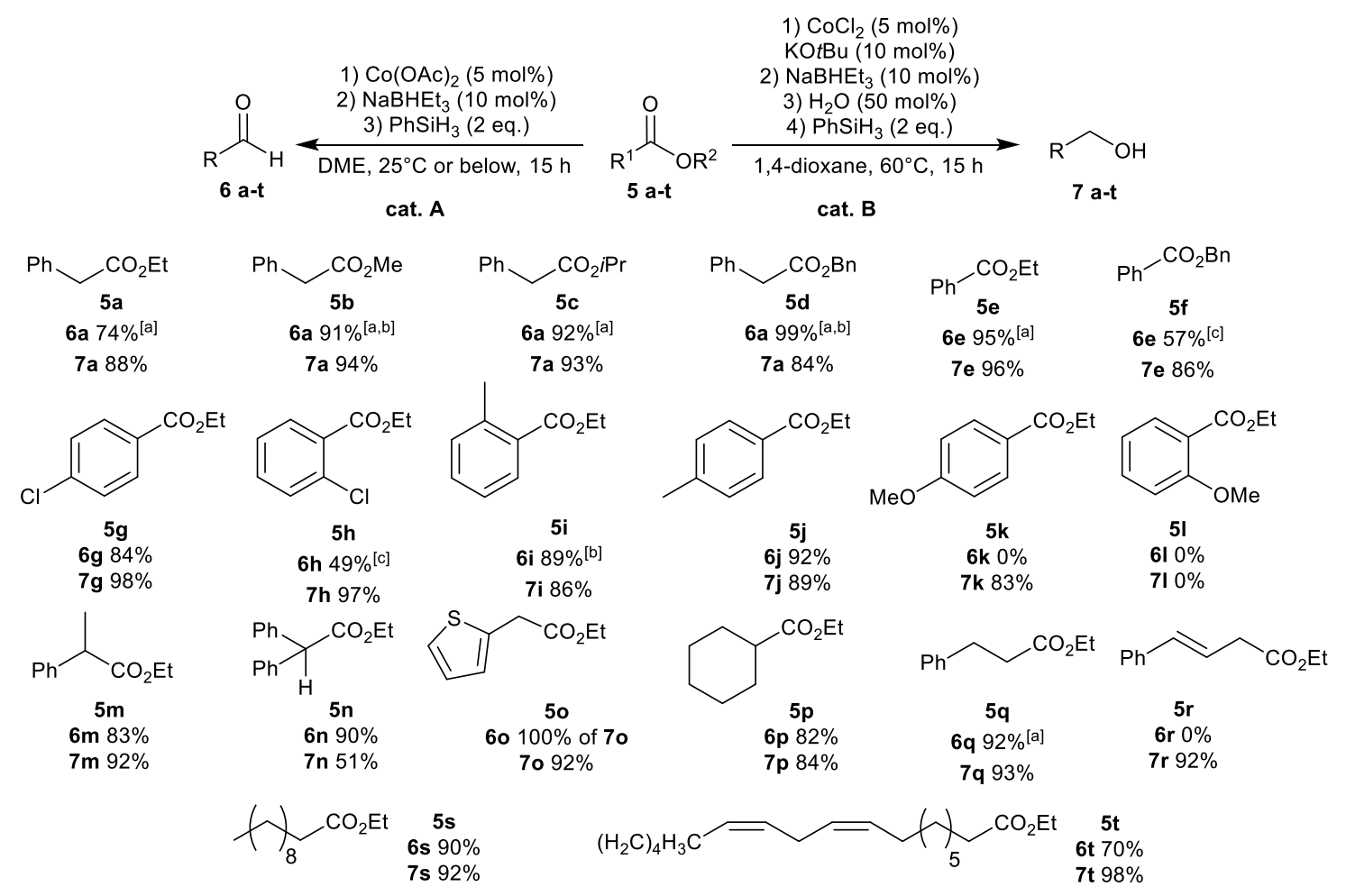

Scheme 2 Scopes of the reactions catalysed by cat. A and cat. B. Isolated yields. [a] Isolated as the 2,4dinitrophenylhydrazone adduct. [b] at $0^{\circ} \mathrm{C}$. [c] at $-20^{\circ} \mathrm{C}$.

The scope of both hydrosilylation reactions was studied for a series of aromatic and aliphatic esters $5 a-t$ under the optimised conditions determined above (Scheme 2). The reaction products, i.e. aldehydes 6a-t and alcohols 7a-t, were all selectively formed using cat. A or cat. B and directly recovered from the resulting crude silyl acetal products through purification by flash chromatography on silica gel. Hydrosilylations implying esters $\mathbf{5 b}, \mathbf{d}, \mathbf{f}, \mathbf{h}, \mathbf{I}$ and cat. A required lower reaction temperatures in order to be fully selective. 2-phenylacetate esters $\mathbf{5 a - d}$ substituted by ethyl, methyl, isopropyl or benzyl groups all led respectively to aldehyde $\mathbf{6 a}$ and alcohol $\mathbf{7 a}$ in high yields. Hydrosilylation of ethyl and benzyl benzoate $5 e, f$ could be also performed readily to afford products $6 e$ and $7 e$ in good to high yields. The reduction of related ortho- and para-substituted ethyl benzoate $\mathbf{5 g}-\mathbf{j}$ proceeded selectively to the desired aldehydes and alcohols in good to high yields independently of the substitution pattern of the reagent. However, if para-methoxy ester $\mathbf{5 k}$ was readily converted to alcohol $\mathbf{7 k}$, aldehyde $\mathbf{6 k}$ was not formed. Furthermore, ortho substitution by a methoxy group led to complete unreactive substrate $\mathbf{5 l}$, which may strongly chelates the catalysts. By comparison, hydrosilylation of sterically hindered 2-phenylacetate $\mathbf{5 m , n}$ proceeded smoothly to the corresponding aldehydes $6 \mathrm{~m}, \mathrm{n}$ and alcohols $7 \mathrm{~m}, \mathrm{n}$. Surprisingly, the reduction of thiophene-based ester $\mathbf{5 o}$ led to alcohol $\mathbf{7 0}$ in high yield for both pathways (cat. A and cat. B). Finally, linear and cyclic aliphatic esters $\mathbf{5 p - t}$ were reduced selectively to the corresponding aldehydes and alcohols in good to high yields, with the exception of ester $5 r$ whose reaction with cat. A did not lead to aldehyde $6 r$.

\section{Characterisations of the catalysts and mechanistic considerations}

The cobalt catalysts were studied by TEM and STEM EDS. The catalyst $\mathbf{A}$ resulting from the reaction of $\mathrm{Co}(\mathrm{OAC})_{2}$ with $\mathrm{NaBHEt}_{3}$ and phenylsilane showed piles of various sizes and thicknesses (Figure 1a). Some were thinner and clearly showed packed nanoparticles (Figure 1b). At HRTEM (ie $>400 \mathrm{kx}$ ), nanoparticles appeared crystalline as plans and diffraction patterns were observed (Figures 1c, 1d, and S1) but their indexation was not obvious as the diffraction data were of average quality. EDX analysis showed the piles were composed of $\mathrm{Co}$ and Fe with the presence of $\mathrm{Ti}$ traces and $\mathrm{Cu}$ from the grid holding the sample (Figure $\mathrm{S} 2$ ). The dispersion of the nanoparticules was studied by STEM EDS elemental mapping without quantification and sizing (Figures 1e-f, S3). 

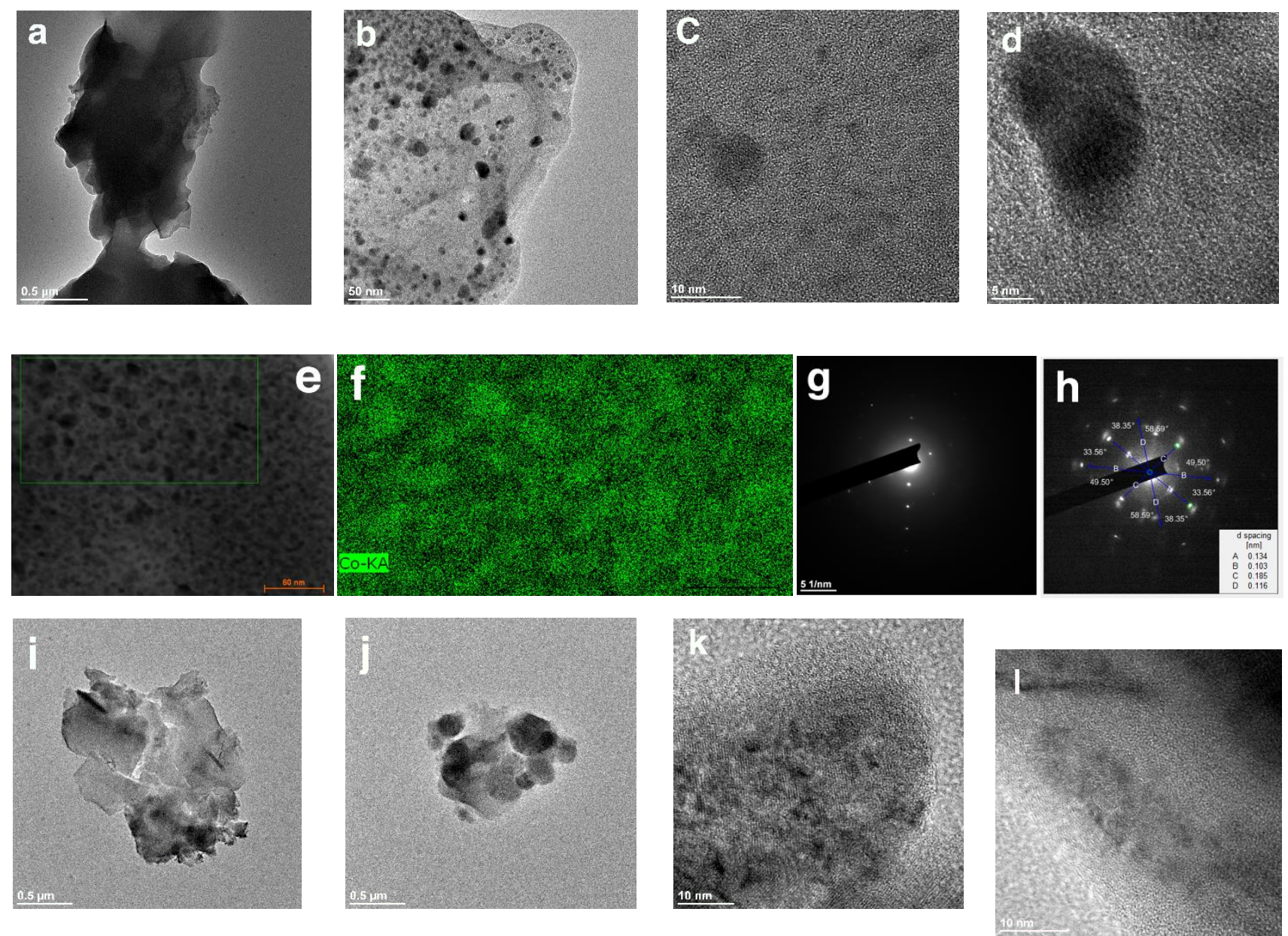

Figure 1 TEM and STEM EDS images of cat. A (a-f) and cat. B (g-l). 1g) Electronic picture of the elemental mapping area by STEM EDS; the green area was scanned. 1h) Elemental mapping area for Co (K-alpha ray @6.925keV) by STEM-EDS.

The nanoparticles observed as dark piles on the electronic picture were predominantly appearing as green piles of $\mathrm{Co}$ on the mapping. The catalyst $\mathrm{B}$ resulting from the reaction of $\mathrm{CoCl}_{2}$ with $\mathrm{KOtBu}$, $\mathrm{NaBHEt}_{3}$, water and phenylsilane was also analysed by TEM in spite of focus problems related to the presence of charges and of the detrimental effect of the beam impact which converted crystalline piles into amorphous ones. At low magnification, piles of various sizes and thicknesses were noticed with small stripes or nanoparticles or combining both (Figures $1 \mathrm{i}, 1 \mathrm{j}$ ). Some needles arranged crosswise were also observed in the piles but they were not always crystalline according the lack of diffraction patterns. At HRTEM, nanoparticles appeared crystalline (Figures $1 \mathrm{k}, 1 \mathrm{l}$ ) and the observed diffraction patterns could be indexed for $\mathrm{Co}(\mathrm{OH})_{2}$ (Figures $1 \mathrm{~g}, 1 \mathrm{~h}, 1 \mathrm{j}$, S4-S6). However, sample was not stable enough to allow any STEM-EDS analysis as nanoparticles were rapidly becoming amorphous or even melting upon effect of the 200kV beam (Figures S7). EDX analysis showed the piles were composed of $\mathrm{Co}, \mathrm{Fe}, \mathrm{Si}, \mathrm{K}$ and $\mathrm{Cl}$ with the presence of $\mathrm{Ti}$ traces and $\mathrm{Cu}$ from the grid holding the sample (Figure $\mathrm{S} 8$ ). The presence of Fe in catalysts $\mathbf{A}$ and $\mathbf{B}$ was also confirmed by X-ray fluorescence (Figure S18) and originated from the Fe residues in the commercial cobalt salts used. The claimed purities of the latter were reagent grade for the $\mathrm{Co}(\mathrm{OAc})_{2}$ and $99+\%$ for the $\mathrm{CoCl}_{2}$. It was worth to note similar reaction outcomes were obtained for both catalytic reactions while using cobalt salts of higher purities, i.e. >99.99\% (Tables S1 and S4). TEM analyses of catalysts A and B prepared without silane were also performed (Figures S9-S17). Piles of various sizes and thicknesses were also observed with various kinds of crystals (needles, sheets...). If nanoparticles appeared crystalline at HRTEM, indexations of the 
diffraction patterns were not obvious (Figures S9-S11 and S12-S16). Moreover, catalyst B sample was rapidly becoming amorphous or even melting upon effect of the 200kV beam (Figure S17).

The catalysts $\mathbf{A}$ and $\mathbf{B}$ were further characterised by their X-ray diffraction (XRD) patterns using reflexion and transmission modes (Figure 2 and Figures S19-S22). The latter allowed working in anhydrous and oxygen free conditions with a better resolution.

a)

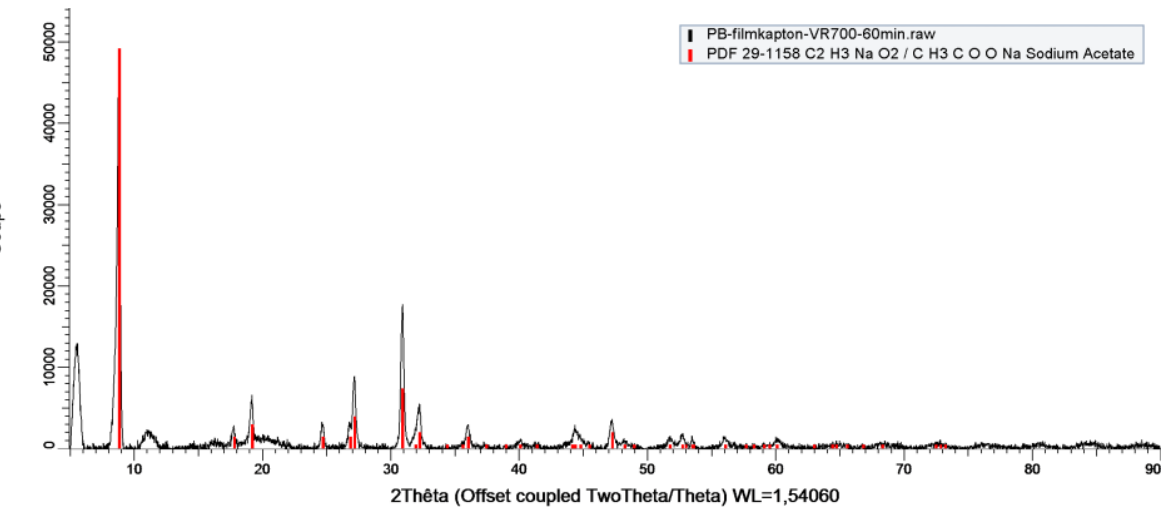

b)

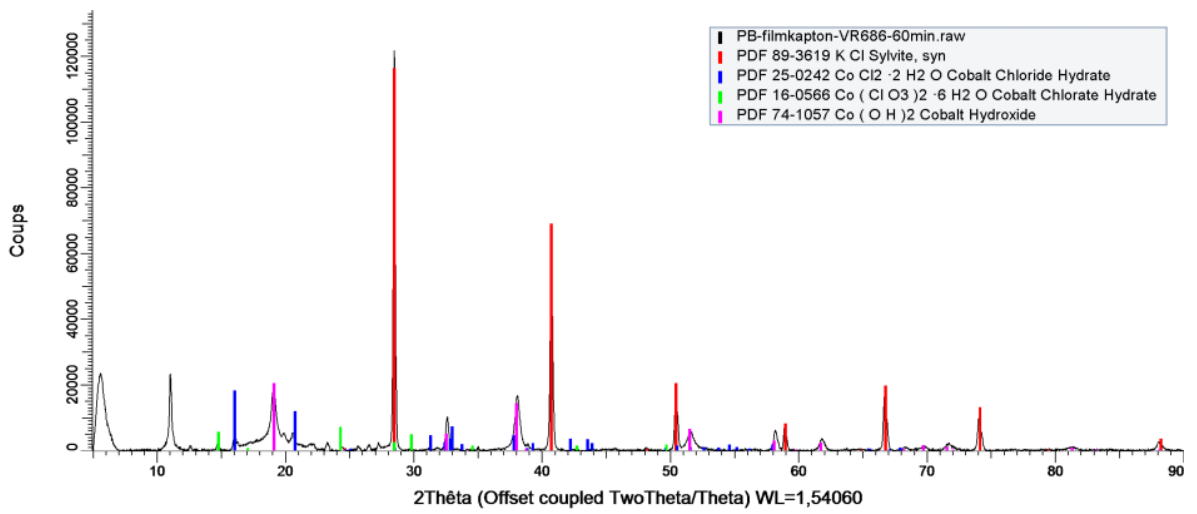

c)

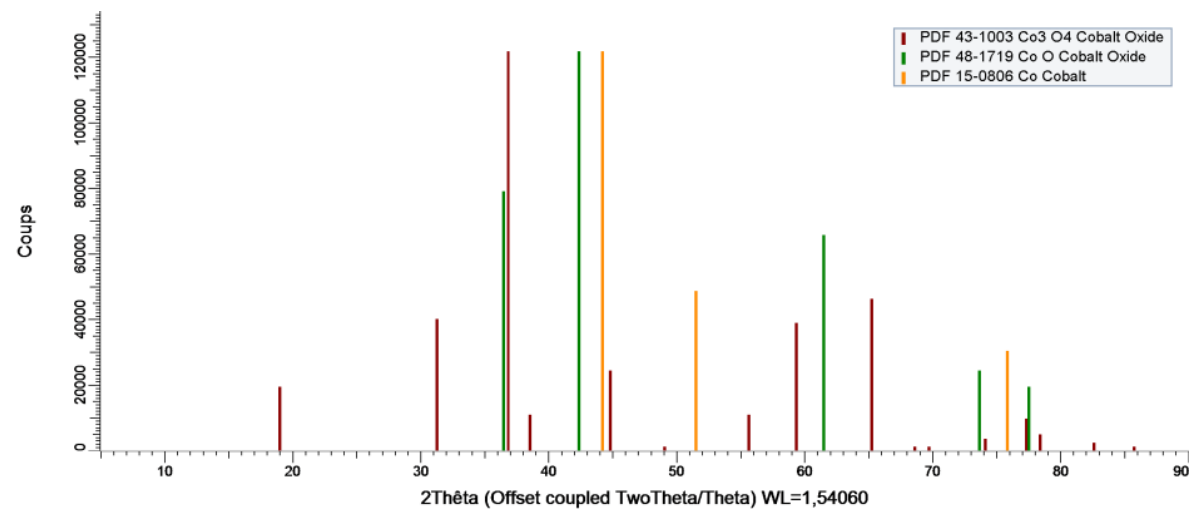

Figure 2 X-ray diffraction patterns of cat. A (a) and cat. B (b) using transmission mode. c) reference diffraction patterns.

We first analysed the catalyst $\mathbf{A}$ resulting from the reaction of $\mathrm{Co}(\mathrm{OAC})_{2}$ with $\mathrm{NaBHEt}_{3}$ and phenylsilane (Figures 2a, 2c). Most of the diffraction patterns were ascribed to $\mathrm{NaOAc}$ without any evidence for the presence of $\mathrm{CoO}, \mathrm{CO}_{3} \mathrm{O}_{4}$ and low valent $\mathrm{Co}(0)$ species. The catalyst $\mathrm{B}$ resulting from the reaction of $\mathrm{CoCl}_{2}$ with $\mathrm{KOtBu}, \mathrm{NaBHEt}_{3}$, water and phenylsilane was also analysed (Figure $2 \mathrm{~b}$ and $2 \mathrm{c}$ ). Most of the observed diffractions were fitted with the XRD patterns of $\mathrm{KCl}$ and $\mathrm{Co}(\mathrm{OH})_{2}$ in accordance with the TEM results. Minor peaks were attributed to remaining $\mathrm{CoCl}_{2}$ and there was no evidence for the presence of $\mathrm{CoO}, \mathrm{CO}_{3} \mathrm{O}_{4}$ and $\mathrm{Co}(0)$ species. 
The catalysts A and B prepared without phenylsilane led to similar diffraction patterns (Figures S23, S24). Additional analyses by Diffuse Reflectance Infrared Fourier Transform Spectroscopy (DRIFTS) confirmed respectively the presence of hydroxide groups for catalyst $\mathbf{B}$ and of OAc function for catalyst A (Figures S25, S26).

X-ray photoelectron spectroscopy (XPS) analyses were then performed in order to determine the chemical composition at the surface of the catalysts. Two types of samples were studied for each catalyst, i.e. cat. A and cat. B, the first being prepared in the presence of silane and second without.

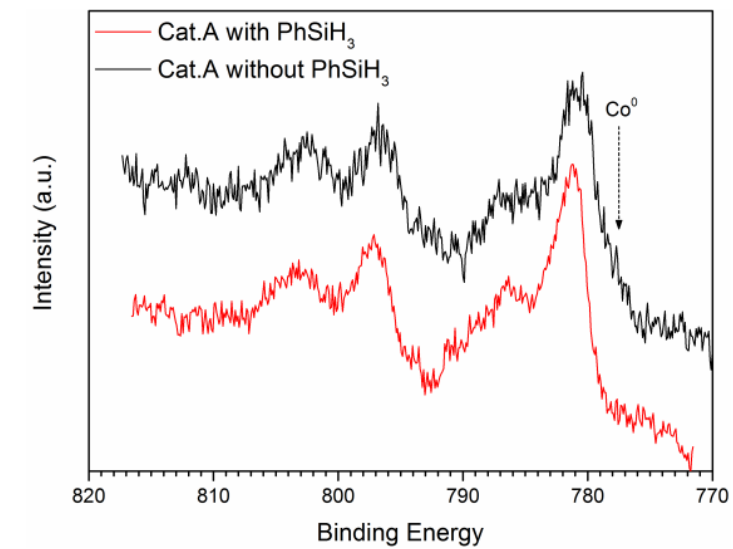

a)

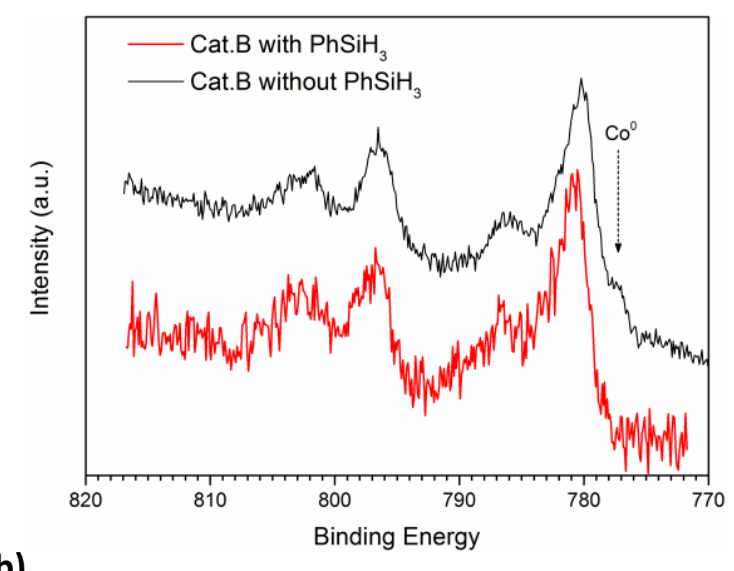

b)

Figure 3 XPS of cat. A (a) and cat. B (b) with or without phenylsilane.

Regarding the catalyst $\mathbf{A}$ based on $\mathrm{Co}(\mathrm{OAc})_{2}$, the full scan spectrum revealed the core levels of the elements $\mathrm{O}, \mathrm{Co}, \mathrm{Na}, \mathrm{C}$ and $\mathrm{Si}$ (Figures S27, S28). An unexpected presence of $\mathrm{Cl}$ was also detected as it was an impurity of the $\mathrm{Co}(\mathrm{OAC})_{2}$ (Figure S29). At the exception of B element, similar core levels were observed for the catalyst $\mathbf{A}$ sample prepared without silane. The cobalt $2 p$ spectrum showed the core level signals of $\mathrm{Co}(\mathrm{II})$ with $\mathrm{Co} 2 \mathrm{p}_{3 / 2}$ at $781 \mathrm{eV}$ and some low valent $\mathrm{Co}(0)$ was only detected for the catalyst $\mathbf{A}$ sample prepared without silane (Figure 3 right). Furthermore, the full scan spectrum of the catalyst $\mathbf{B}$ based on $\mathrm{CoCl}_{2}$ revealed the core levels of the elements $\mathrm{O}, \mathrm{Co}, \mathrm{Na}, \mathrm{B}, \mathrm{Cl}, \mathrm{C}, \mathrm{K}$ and $\mathrm{Si}$ (Figures S30, S31). Similar core levels were observed for the catalyst B sample prepared without silane. The cobalt $2 p$ spectrum showed the core level signals of Co(II) with Co $2 p_{3 / 2}$ at $781 \mathrm{eV}$ and some low valent $\mathrm{Co}(0)$ was only detected for the catalyst $\mathbf{B}$ sample prepared without silane (Figure 3 left).

Following the catalysts characterisations asserting the presence of $\mathrm{Co}(\mathrm{II})$ and $\mathrm{Co}(0)$ species, we underwent some control experiments (Scheme 3). Regarding the reduction of ester $\mathbf{5 a}$ to aldehyde $\mathbf{6 a}$ using $\mathrm{Co}(\mathrm{OAC})_{2}$ as pre-catalyst (cat. A), we noticed the reaction required the addition of the reducing agent $\mathrm{NaBHEt}_{3}$ to operate and thus confirmed low valent $\mathrm{Co}(0)$ was most likely the active species involved (Scheme 3, equation 1). Furthermore, considering the reduction of ester $\mathbf{5 a}$ to alcohol $\mathbf{7 a}$ using $\mathrm{CoCl}_{2}$ as pre-catalyst (cat. B) and relying on the results obtained by X-ray diffraction and DRIFTS analyses, we confirmed the reaction were effectively run within the optimised conditions by using $\mathrm{Co}(\mathrm{OH})_{2}$ instead of $\mathrm{CoCl}_{2}$ (Scheme 3, equation 2). Whereas in that case KOtBu additive could be skipped, we demonstrated ester $\mathbf{5 a}$ was not reduced without addition of $\mathrm{NaBHEt}_{3}$ and therefore confirmed low valent $\mathrm{Co}(0)$ was likely to be the involved active species (Scheme 3, equation 2). Indeed, as the single uses of $\mathrm{KOtBu}, \mathrm{Co}(\mathrm{OH})_{2}$ or $\mathrm{Co}(\mathrm{OAc})_{2}$ were not catalysing the reactions (Scheme 3, Table S5, entry 5), any base catalysed hydrosilylation ${ }^{17}$ could be excluded. Furthermore, if in the past the single use of $\mathrm{NaBHEt}_{3}$ was shown to catalyse several hydrosilylation reactions, ${ }^{18}$ this hydride here directly reduced the $\mathrm{Co}(\mathrm{II})$ salts to lead to low valent $\mathrm{Co}(0)$ as active species. The critical role of the latter was confirmed by the two following control experiments using simply $\mathrm{NaBHEt}_{3}$ as a catalyst 
without any cobalt salt and base. Within the reaction conditions used for the reduction of ester $5 \mathbf{a}$ to aldehyde 6 a, the selectivity was reversed in favour of alcohol 7a (Table S1, entries 2, 4, 10).

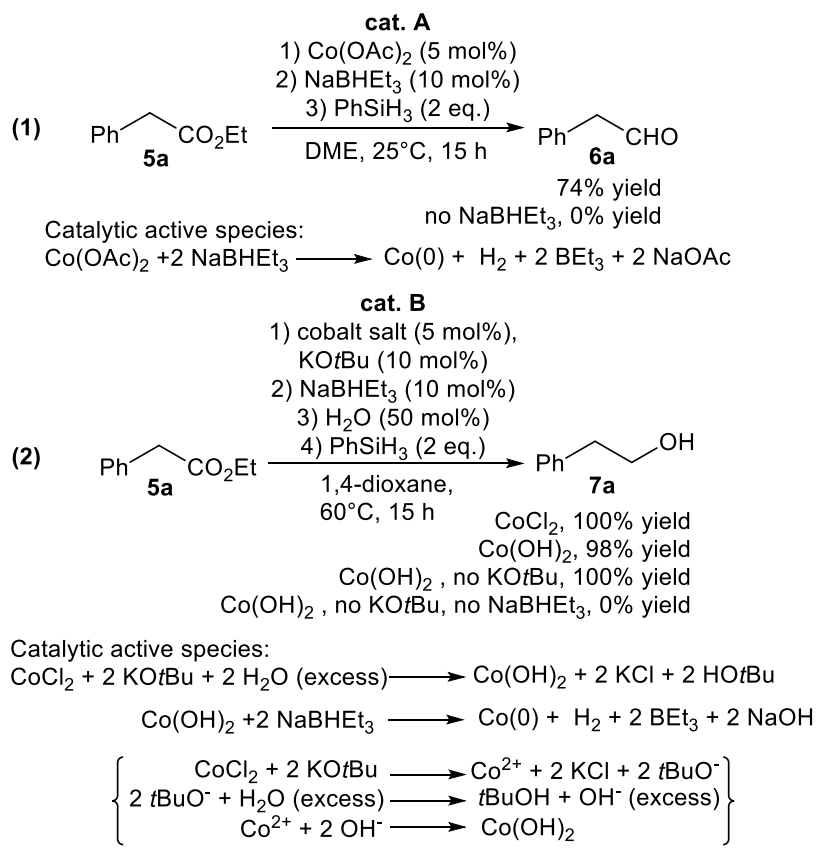

Scheme 3 Control experiments regarding the catalytic active species.

Moreover, while applying the conditions used for the reduction of ester $5 \mathbf{a}$ to alcohol $7 \mathbf{a}$, the latter was prepared in a much lower yield (39\% in 5 hours) as compared to quantitative Co catalysed reactions (Tables S4, entries 3, 5, 10). If cat. B activation required a base like many earth-abundant metal catalysts, ${ }^{19}$ we observed the reaction selectivity and yield were dependent of the type of base (Scheme 3 - equation 2, table 2 - entry 7 and table S5). Moreover, in the case of cat. A, the high reaction selectivity towards the aldehyde 6 a was lost using a catalytic amount of base, alcohol 7a being obtained (Table 1, entry 6 ). Hence, considering our previous report on the selective hydrosilylation of esters to aldehydes using a homogeneous $\operatorname{Ir}(\mathrm{III})$ metallacycle catalyst, ${ }^{16 \mathrm{~d}}$ we can hypothesize the trapping of reactive silane intermediates is the key parameter controlling the hydrosilylation of esters towards aldehydes. Herein, such reaction selectivity was only observed applying $\mathrm{Co}(\mathrm{OAc})_{2}$ and $\mathrm{Co}(\mathrm{acac})_{2}$ (Tables S1 and S4) and underlined a possible role of the organic acetate or acac anion in this process.

Finally, we investigated the recycling of catalysts $\mathbf{A}$ and $\mathbf{B}$ (Tables S8 and S9). If any new cycle required obviously the further addition of the co-reactant phenyl silane ( 2 eq.), we noticed in each case the use of a subsequent catalytic amount (10 mol\%) of $\mathrm{NaBHEt}_{3}$ was necessary at the beginning of any cycle in order to allow the catalytic reactions to proceed. Along the cycles, it was worth to note catalyst $\mathbf{A}$ was no longer selective for aldehyde $\mathbf{6 a}$ as around $23 \%$ of alcohol $7 \mathbf{7 a}$ was formed as respected to 6 a starting from the second run. However, catalyst B was successfully reused up to 4 cycles without significant loss of selectivity.

\section{Conclusions}

To summarise, we have developed novel and original cobalt catalysts for the selective hydrosilylation of esters to aldehydes or alcohols while using simple Co(II) salts without any costly and air sensitive ligands. Catalyst characterisations indicate the materials were partially crystalline with the presence of nanoparticles. Though Co(II) was the main oxidation state observed in the prepared catalysts, some $\mathrm{Co}(0)$ was also present. Control experiments confirmed low valent $\mathrm{Co}(0)$ was the active species 
involved. At that stage, further investigations are needed before addressing the accurate role of the base additive and of the acetate anion on the reaction selectivities and mechanisms. Further studies of such catalysts and their reactivity will be reported in due time.

\section{Experimental}

\section{General procedure for the catalytic reactions.}

\section{- Reactions implying $\mathrm{Co}(\mathrm{OAc})_{2}$ precursor, e.g. cat. A:}

$\mathrm{Co}(\mathrm{OAc})_{2} .4 \mathrm{H}_{2} \mathrm{O}(3.8 \mathrm{mg}, 5 \mathrm{~mol} \%, 0.015 \mathrm{mmol})$ was introduced into a Schlenk tube and dried under vacuum during 15 minutes. Under nitrogen, dry DME $(2 \mathrm{~mL})$ was transferred and the resulting solution was stirred at $60^{\circ} \mathrm{C}$. After 15 minutes, $\mathrm{NaBHEt}_{3}(30 \mu \mathrm{L}, 1 \mathrm{M}$ in toluene, $10 \mathrm{~mol} \%, 0.03 \mathrm{mmol})$ was added. After 5 minutes of additional stirring, $\mathrm{PhSiH}_{3}(74 \mu \mathrm{L}, 2$ eq., $0.6 \mathrm{mmol})$ was added followed by the ester ( $0.3 \mathrm{mmol}, 1$ eq.). The reaction mixture was then heated at $25^{\circ} \mathrm{C}$ under stirring during 15 hours. Reactions proceeded also on a $3 \mathrm{mmol}$ scale of ester.

\section{- Reactions implying $\mathrm{CoCl}_{2}$ precursor, e.g. cat. B:}

In a glovebox, $\mathrm{CoCl}_{2}(1.95 \mathrm{mg}, 5 \mathrm{~mol} \%, 0.015 \mathrm{mmol}), \mathrm{KOtBu}(3.36 \mathrm{mg}, 10 \mathrm{~mol} \%, 0.03 \mathrm{mmol}$ ) were introduced into a Schlenk tube. Under nitrogen, dry dioxane $(2 \mathrm{~mL})$ was transferred and the resulting mixture was heated at $60^{\circ} \mathrm{C}$. After 15 minutes, NaBHEt ${ }_{3}(30 \mu \mathrm{L}, 1 \mathrm{M}$ in toluene, $10 \mathrm{~mol} \%, 0.03 \mathrm{mmol}$ ) and water $(2.7 \mu \mathrm{L}, 50 \mathrm{~mol} \%, 0.15 \mathrm{mmol})$ were added. After 5 additional minutes of stirring, $\mathrm{PhSiH}_{3}(74$ $\mu \mathrm{L}, 2$ eq., $0.6 \mathrm{mmol})$ was added followed by the ester $(0.30 \mathrm{mmol}, 1$ eq. $)$. The reaction mixture was then heated at $60^{\circ} \mathrm{C}$ under stirring during 15 hours. Reactions proceeded also on a $3 \mathrm{mmol}$ scale of ester.

To monitor the progress of the reactions, aliquots $(0.1 \mathrm{~mL})$ were taken at defined times, filtered through Celite with a $\mathrm{CH}_{2} \mathrm{Cl}_{2}$ wash $(3 \mathrm{~mL})$, and analysed by $\mathrm{GC}$. At the end of each reaction, the crude product was filtered through Celite with a $\mathrm{CH}_{2} \mathrm{Cl}_{2}$ wash $(3 \mathrm{~mL})$ then purified by flash chromatography or preparative TLC. Volatile aldehyde products were isolated as 2,4-dinitrophenylhydrazone adducts as follows. After reaction, the resulting crude mixture was dried over $\mathrm{MgSO}_{4}$ and diluted with ethanol $(1 \mathrm{~mL})$. The resulting solution was treated with $0.5 \mathrm{~mL}$ of Brady's reagent [solution of 2,4dinitrophenylhydrazine $(0.3 \mathrm{~g}), \mathrm{H}_{2} \mathrm{O}(1.5 \mathrm{~mL})$, ethanol $(5 \mathrm{~mL})$ and $\mathrm{H}_{2} \mathrm{SO}_{4}$ conc. $(1 \mathrm{~mL})$ ] for 30 min with vigorous stirring. The resulting orange precipitate was isolated by filtration through filter paper, washed and triturated with ethanol $(10 \mathrm{~mL})$ and finally dried under vacuum.

\section{Conflict of Interest}

There is no conflict of interest to declare.

\section{Acknowledgements}

The University of Lille 1 is acknowledged for PhD fellowship (V. R.). The CNRS, the Chevreul Institute (FR 2638), the Ministère de l'Enseignement Supérieur et de la Recherche, the Région Nord - Pas de Calais and the FEDER are acknowledged for supporting and funding partially this work. Mrs C. Delabre (UCCS) is thanked for GC, GC-MS and elemental analyses. Dr M. Marinova (UMET, CNRS UMR8207 Univ. of Lille) is thanked for preliminary TEM analyses. Dr. K. Philippot (LCC-CNRS UPR8241) is thanked for discussions regarding this project and chemistry of nanoparticles. Dr. F. Bisaro is thanked for few preliminary experiments and related discussions. Ms D. Kalocsai (Erasmus exchange between ENSCL France and University of Budapest - Hungary) is thanked for her help with some experimental work at the end of the study. 


\section{Notes and references}

1) a) M. L. Clarke, and G. J. Roff, in The Handbook of Homogeneous Hydrogenation (Eds.: J. G. de Vries, C. J. Elsevier), Wiley-VCH, Weinheim, 2007, pp. 413-454; b) Modern Reduction Methods (Eds.: P. G. Andersson, I. J. Munslow), Wiley, Hoboken, 2008; c) P. A. Dub, and T. Ikariya, ACS Catal., 2012, 2, 17181741; d) J. March, in Advanced Organic Chemistry: Reactions, Mechanisms and Structures, 7th ed., Wiley-VCH, Weinheim, 2013.

2) a) J. Zhang, G. Leitus, Y. Ben-David, and D. Milstein, Angew. Chem. Int. Ed., 2006, 45, 1113; b) L. A. Saudan, C. M. Saudan, C. Debieux, and P. Wyss, Angew. Chem. Int. Ed., 2007, 46, 7473; c) W. Kuriyama, T. Matsumoto, O. Ogata, Y. Ino, K. Aoki, S. Tanaka, K. Ishida, T. Kobayashi, N. Sayo, and T. Saito, Org. Process Res. Dev., 2012, 16, 166.

3) a) T. Zell, Y. Ben-David, and D. Milstein, Angew. Chem. Int. Ed., 2014, 53, 4685; b) S. Werkmeister, K. Junge, B. Wendt, E. Alberico, H. Jiao, W. Baumann, H. Junge, F. Gallou, and M. Beller, Angew. Chem. Int. Ed., 2014, 53, 8722; c) S. Elangovan, B. Wendt, C. Topf, S. Bachmann, M. Scalone, A. Spannenberg, H. Jiao, W. Baumann, K. Junge, and M. Beller, Adv. Synth. Catal., 2016, 358, 820; d) S. Chakraborty, H. Dai, P. Bhattacharya, N. T. Fairweather, M. S. Gibson, J. A. Krause, and H. Guan, J. Am. Chem. Soc., 2014, 136, 7869; e) D. S. Mérel, M. L. T. Do, S. Gaillard, P. Dupau, and J.-L. Renaud, Coord. Chem. Rev., 2015, 288, 50; f) P. Gajewski, A. Gonzalez-de-Castro, M. Renom-Carrasco, U. Piarulli, C. Gennari, J. G. de Vries, L. Lefort, and L. Pignataro, ChemCatChem, 2016, 8, 3431.

4) a) S. Elangovan, M. Garbe, H. Jiao, A. Spannenberg, K. Junge, and M. Beller, Angew. Chem. Int. Ed., 2016, 55, 15364; b) N. A. Espinosa-Jalapa, A. Nerush, L. J. W. Shimon, G. Leitus, L. Avram, Y. Ben-David, and D. Milstein, Chem. Eur. J., 2017, 23, 5934; c) M. B. Widegren, G. J. Harkness, A. M. Z. Slawin, D. B. Cordes and M. L. Clarke, Angew. Chem. Int. Ed., 2017, 56, 5825; d) R. van Putten, E. Uslamin, M. Garbe, C. Liu, A. Gonzalez-de-Castro, M. Lutz, K. Junge, E. J. M. Hensen, M. Beller, L. Lefort, and E. A. Pidko, Angew. Chem. Int. Ed., 2017, 56, 7531.

5) a) D. Srimani, A. Mukherjee, A. F. G. Goldberg, G. Leitus, Y. Diskin-Posner, L. J. W. Shimon, Y. Ben David, and David Milstein, Angew. Chem. Int. Ed., 2015, 54, 12357; b) T. J. Korstanje, J. I. van der Vlugt, C. J. Elsevier, and B. de Bruin, Science, 2015, 350, 298; c) J. Yuwen, S. Chakraborty, W. W. Brennessel, and W. D. Jones, ACS Catal., 2017, 7, 3735; d) K. Junge, B. Wendt, A. Cingolani, A. Spannenberg, Z. Wei, H. Jiao, and M. Beller, Chem. Eur. J., 2018, 24, 1046.

6) a) J. Osuna, D. De Caro, C.Amiens, B. Chaudret, E. Snoeck, M. Respaud, J.-M. Broto and A. Fert, J. Phys. Chem., 1996, 100, 14571; b) W. Hess, J. Treutwein, and G. Hilt, Synthesis, 2008, 40, 3537; c) M. S. Holzwarth, and B. Plietker, ChemCatChem, 2013, 5, 1650; d) P. Gandeepan, C. H. Cheng, Acc. Chem. Res., 2015, 48, 1194; e) F. Chen, A.-E. Surkus, L. He, M.-M. Pohl, J. Radnik, C. Topf, K. Junge, and M. Beller, J. Am. Chem. Soc., 2015, 137, 11718; f) F. Chen, C. Topf, J. Radnik, C. Kreyenschulte, H. Lund, M. Schneider, A. E. Surkus, L. He, K. Junge, and M. Beller, J. Am. Chem. Soc., 2016, 138, 8781; g) T. Schwob, and R. Kempe, Angew. Chem. Int. Ed., 2016, 55, 15175; h) Z. Wei, Y. Chen, J. Wang, D. Su, M. Tang, S. Mao, and Y. Wang, ACS Catal., 2016, 6, 5816; i) R. V. Jagadeesh, K. Murugesan, A. S. Alshammari, H. Neumann, M.-M. Pohl, J. Radnik, and M. Beller, Science, 2017, 358, 326; j) B. S. Kumar, A. J. Amali, and K. Pitchumani, Mol. Cat., 2018, 448, 153; k) S. Sandl, F. Schwarzhuber, S. Pöllath, J. Zweck, and A. Jacobi von Wangelin Chem. Eur. J., 2018, 24, 3403.

7) a) Y. Takegami, T. Ueno, and T. Fujii, Bull. Chem. Soc. Jpn., 1965, 38, 1279; b) F. K. Schmidt, Y. Titova, L. B. Belykh, V. A. Umanets, and S. S. Khutsishvili, Russ. J. Gen. Chem., 2012, 82, 1334. 
8) For the hydrosilylation of esters to alcohols, see: a) S. C. Berk, K. A. Kreutzer, and S. L. Buchwald, J. Am. Chem. Soc., 1991, 113, 5093; b) S. C. Berk, and S. L. Buchwald, J. Org. Chem., 1992, 57, 3751; c) D. J. Parks, and W. E. Piers, J. Am. Chem. Soc., 1996, 118, 9440; d) H. Mimoun, J. Org. Chem., 1999, 64, 2582; e) T. Ohta, M. Kamiya, M. Nobutomo, K. Kusui, and I. Furukawa, Bull. Chem. Soc. Jpn., 2005, 78, 1856; f) A. C. Fernandes, and C. C. Romão, J. Mol. Catal. A, 2006, 253, 96; g) S. Das, K. Möller, K. Junge, and M. Beller, Chem. Eur. J., 2011, 17, 7414; h) L. Pehlivan, E. Métay, S. Laval, W. Dayoub, D. Delbrayelle, G. Mignani, and M. Lemaire, Eur. J. Org. Chem., 2011, 7400; i) O. O. Kovalenko, and H. Adolfsson, Chem. Eur. J., 2015, 21, 2785.

9) a) B. Marciniec, H. Maciejewski, C. Pietraszuk and P. Pawluć in Hydrosilylation: A Comprehensive Review on Recent Advances, (Ed. B. Marciniec), Springer, Heidelberg, 2009; b) D. Addis, S. Das, K. Junge and M. Beller, Angew. Chem. Int. Ed., 2011, 50, 6004; c) K. Revunova and G. I. Nikonov, Dalton Trans., 2015, 44, 840; d) J. Pesti and G. L. Larson, Org. Process Res. Dev. 2016, 20, 1164; e) Mark C. Lipke, Allegra L. Liberman-Martin, and T. Don Tilley, Angew. Chem. Int. Ed., 2017, 56, 2260.

10) a) D. Bézier, G. T. Venkanna, L. C. Misal Castro, J. Zheng, T. Roisnel, J.-B. Sortais, and C. Darcel, Adv. Synth. Catal., 2012, 354, 1879; b) L. C. Misal Castro, H. Li, J.-B. Sortais, and C. Darcel, Chem. Commun., 2012, 48, 10514; c) S. Das, Y. Li, K. Junge, and M. Beller, Chem. Commun., 2012, 48, 10742; d) K. Junge, B. Wendt, S. Zhou, and M. Beller, Eur. J. Org. Chem., 2013, 2013, 2061; e) H. Li, L. C. Misal Castro, J. Zheng, T. Roisnel, V. Dorcet, J.-B. Sortais, and C. Darcel, Angew. Chem. Int. Ed., 2013, 52, 8045; f) A. J. Ruddy, C. M. Kelly, S. M. Crawford, C. A. Wheaton, O. L. Sydora, B. L. Small, M. Stradiotto, and L. Turculet, Organometallics, 2013, 32, 5581.

11) a) J. Zheng, S. Chevance, C. Darcel, and J.-B. Sortais, Chem. Commun., 2013, 49, 10010; b) T. K. Mukhopadhyay, M. Flores, T. L. Groy, and R. J. Trovitch, J. Am. Chem. Soc., 2014, 136, 882; c) R. J. Trovitch, Acc. Chem. Res., 2017, 50, 2842; d) C. M. Kelly, R. McDonald, O. L. Sydora, M. Stradiotto, and L. Turculet, Angew. Chem. Int. Ed., 2017, 56, 15901.

12) a) F. Agbossou, J.-F. Carpentier, and A. Mortreux, Chem. Rev., 1995, 95, 2485; b) G. T. Whiteker, and C. J. Cobley, Top. Organomet. Chem., 2012, 42, 35; c) M. Vilches-Herrera, L. Domke, and A. Börner, ACS Catal., 2014, 4, 1706.

13) a) D. Romano, R. Villa, and F. Molinari, ChemCatChem, 2012, 4, 739; b) S. E. Davis, M. S. Ide, and R. J. Davis, Green Chem., 2013, 15, 17.

14) a) L. I. Zakharkin, and I. M. Khorlina, Tetrahedron Lett., 1962, 3, 619; b) N. Z. Burns, P. S. Baran, and R. W. Hoffmann, Angew. Chem. Int. Ed., 2009, 48, 2854; c) D. Webb, and T. F. Jamison, Org. Lett., 2012, 14, 568 and references therein.

15) a) M. Igarashi, R. Mizuno, and T. Fuchikami, Tetrahedron Lett., 2001, 42, 2149; b) J. Nakanishi, H. Tatamidani, Y. Fukumoto, and N. Chatani, Synlett, 2006, 869; c) D. J. Parks, J. M. Blackwell, and W. E. Piers, J. Org. Chem., 2000, 65, 3090; d) C. Cheng, and M. Brookhart, Angew. Chem. Int. Ed., 2012, 51, 9422; e) H. Li, L. C. Misal Castro, J. Zheng, T. Roisnel, V. Dorcet, J.-B. Sortais, and C. Darcel, Angew. Chem. Int. Ed., 2013, 52, 8045.

16) a) Y. Corre, W. Iali, M. Hamdaoui, X. Trivelli, J.-P. Djukic, F. Agbossou-Niedercorn, and C. Michon, Catal. Sci. Technol., 2015, 5, 1452; b) C. Michon, K. Maclntyre, Y. Corre, and F. Agbossou-Niedercorn, ChemCatChem, 2016, 8, 1755; c) Y. Corre, C. Werlé, L. Brelot-Karmazin, J.-P. Djukic, F. AgbossouNiedercorn, and C. Michon, J. Mol. Catal. A, 2016, 423, 256; d) Y. Corre, V. Rysak, F. Capet, J.-P. Djukic, F. Agbossou-Niedercorn, and C. Michon, Chem. Eur. J., 2016, 22, 14036; e) Y. Corre, X. Trivelli, F. Capet, J.-P. Djukic, F. Agbossou-Niedercorn, and C. Michon, ChemCatChem, 2017, 9, 2009; f) V. Rysak, Y. Corre, 
F. Agbossou-Niedercorn, and C. Michon, Chimica OGGI - Chemistry Today, 2017, 35, 27; g) Y. Corre, V. Rysak, X. Trivelli, F. Agbossou-Niedercorn, and C. Michon, Eur. J. Org. Chem., 2017, 2017, 4820.

17) a) M. Hojo, C. Murakami, A. Fujii and A. Hosomi, Tetrahedron Lett., 1999, 40, 911; b) Y. Izumi and M. Onaka, J. Mol. Catal., 1992, 74, 35; c) J. A. Fernández-Salas, S. Manzini and S. P. Nolan, Chem. Commun., 2013, 49, 9758; d) K. Revunova, and G. I. Nikonov, Chem. Eur. J., 2014, 20, 839; e) K. Revunova, and G. I. Nikonov, Dalton Trans., 2015, 44, 840.

18) M. G. Manas, L. S. Sharninghausen, D. Balcells, and R. H. Crabtree, New J. Chem., 2014, 38, 1694.

19) J. H. Docherty, J. Peng, A. P. Dominey, and S. P. Thomas, Nature Chem., 2017, 9, 596. 